\title{
Martos Molina, Marta (2014): Las rutas culturales en el desarrollo territorial. Estudio de casos y propuestas para el Camino Real e Intercontinental. Sevilla: Universidad Internacional de Andalucía, 224 pp. ISBN: 978-84-7993-252-7
}

El turismo ha sido, desde los tiempos del Grand Tour un hecho social relevante por todas las consecuencias tanto directas como indirectas que suscita. Precisamente el Grand Tour, que en España tenía su correspondencia con el denominado Correr Cortés, suponía viajes organizados como primigenias rutas culturales en las que los jóvenes aristócratas ingleses viajaban para completar su formación y aprender las artes de la diplomacia, generaban a su alrededor un significativo tejido de realidades multidimensionales como la de creación de alojamientos, evolución de un lenguaje destinado a la complacencia de los visitantes o el avance de determinados servicios, entre otros, permitiendo así a diferentes entornos su paulatino desarrollo. Hoy en día el turismo es un fenómeno de enorme trascendencia en las sociedades tardomodernas y no solo desde un punto de vista económico, sino social y cultural. Muestra de su importancia es el desarrollo teórico y empírico que están viviendo los estudios turísticos tanto en nuestro país como en el extranjero. En España no debe resultar extraño, pues se calcula que el 11 por ciento del Producto Interior Bruto deriva del mismo y que más de dos millones de personas encuentran ocupación en el sector. El estudio que aquí se reseña ha sido elaborado por Marta Martos Molina, que ya había publicado previamente sobre el impacto del turismo cultural en entornos urbanos. En este caso, presenta una investigación sobre el impacto de las denominadas rutas culturales en el desarrollo del territorio. En concreto, analiza una serie de casos paradigmáticos y elabora una propuesta para el Camino Real e Intercontinental.

El libro está dividido en tres partes claramente diferenciadas. En primer lugar, realiza un análisis teórico de los principales conceptos implicados en la investigación. En concreto, comienza realizando un análisis del impacto del turismo en el desarrollo territorial para, acto seguido, describir como es utilizado el patrimonio cultural como un recurso turístico. Se analizan las bondades y la problemática de convertir el patrimonio cultural de una región concreta en un producto turístico. Finalmente, aplica este modelo para analizar cómo una itinerario cultural, que es parte del patrimonio de un territorio, puede convertirse en una ruta turística cultural, es decir, en un producto turístico que pueda ser comercializado. Dicho de otro modo, la existencia de un conjunto de bienes culturales materiales e inmateriales organizados en torno a un itinerario no garantiza que sea posible explotar turísticamente ese recurso. Es necesario, afirma, organizar y planificar una ruta turística que habilite la explotación de dicho recurso, lo que lo convierte en un producto.

Posteriormente, realiza un análisis empírico en el que trata de delimitar su objeto de estudio. Para ello, organizó un Focus Group con el objetivo de delimitar las rutas turísticas que posteriormente serían objeto de estudio de caso, de un lado, y, de otro, seleccionar las variables a analizar en cada uno de los casos estudiados. Dichas variables se organizaron en torno a tres grandes macroejes: dimensión social, dimensión económica y dimensión patrimonial-ambiental. Desde este punto de partida se pasó al análisis de casos. En concreto se analizaron las siguientes rutas turísticas: Camino del Cid, ruta de los Castillos y las Batallas, rutas literarias en Barcelona, ruta de Antequera, ruta gastronómica Sabores de San Sebastián, ruta del Vino Montilla-Moriles y el Camino de Santiago. Un elemento significativo de las conclusiones es que el éxito de estas rutas depende, en buena medida, de la imbricación del producto turístico con la sociedad en la que opera. Las rutas exitosas descansa en una conexión íntima entre la iniciativa privada y pública, y entre la industria y la sociedad en la que opera.

Finalmente, Marta Martos trata de elaborar una propuesta a través de la herramienta del "cuadro de mando", con el objetivo de dinamizar las rutas culturales para una adecuada gestión del producto turístico. En concreto, se plantea la posibilidad de elaborar un cuadro de mandos para el Camino Real e Intercontinental que está auspiciado por la UNESCO y el CIIC (Comité Internacional de Itinerarios Culturales). "El Camino Real se estructura en dos ejes o itinerarios en los que se definió la ruta obligada de tránsito entre la Península Ibérica, Canarias, América y Filipinas por una parte (eje Este-Oeste) y entre el Caribe, América del Norte y América del Sur, por otra" (p. 149). En este caso, lo que se propone es un cuadro de mando para la adecuada gestión de este corredor cultural, que la autora estructura en torno a tres ejes clave: económico, patrimonial y social, en clara referencia al análisis realizado con anterioridad. Cada uno de ello, a su vez, está descompuesto en una serie de variables e indicadores. A través del mismo podría esperarse que mejorara la gestión de un proyecto de tal envergadura.

Esta idea parece obvia, esto es, la idea de que un proceso como el turismo deba ser medido y evaluado $y, \sin$ embargo, no lo es tanto. En sus conclusiones la autora aún debe argumentar que "la idea de monitorizar la gestión turística no es descabellada" (p.168). Esto es un indicador no solo del actual modelo 
turístico, muchas veces construido por "ensayo y error", sino del estado del "emprendimiento". Muchas veces sobran ganas e imaginación y otras falta análisis y evaluación. Encontramos, en definitiva, una valiosa aportación al campo de la investigación y la gestión turística, que puede ser del interés tanto de los académicos interesados por el fenómeno turístico como de los gestores turísticos. Con ello, se trata de unir teoría y praxis en un intento de fundamentar las prácticas de un sector tan importante para la economía española como es el turismo.
Rubén J. Pérez Redondo Universidad Rey Juan Carlos, Madrid, España rubenjose.perez@urjc.es Recibida: $15-10-2014$ Aceptada: 07-11-2014

(c) (1) (3) 